\title{
Material and solar cell research in high efficiency micromorph tandem solar cell
}

\author{
Razagh Hafezi ${ }^{1}$, Soroush Karimi ${ }^{2}$,Sharie Jamalzae ${ }^{3}$, Masoud Jabbari ${ }^{4}$ \\ 1Electrical Department, Safashahr Branch , Islamic Azad University, Safashahr, Iran \\ 2Electrical Department, Safashahr Branch , Islamic Azad University, Safashahr, Iran \\ 3Electrical Department, Safashahr Branch , Islamic Azad University, Safashahr, Iran \\ ${ }^{4}$ Electrical Department, Marvdasht Branch , Islamic Azad University, Marvdasht, Iran
}

\begin{abstract}
"Micromorph" tandem solar cells consisting of a microcrystalline silicon bottom cell and an amorphous silicon top cell are considered as one of the most promising new thin-film silicon solar-cell concepts. Their promise lies in the hope of simultaneously achieving high conversion efficiencies at relatively low manufacturing costs. The concept was introduced by IMT Neuchâtel, based on the VHF-GD (very high frequency glow discharge) deposition method. The key element of the micromorph cell is the hydrogenated microcrystalline silicon bottom cell that opens new perspectives for low-temperature thin-film crystalline silicon technology. This paper describes the use, within $p-$ $i-n$ - and n-i-p-type solar cells, of hydrogenated amorphous silicon ( $a-S i: H)$ and hydrogenated microcrystalline silicon (_c-Si:H) thin films (layers), both deposited at low temperatures (200_C) by plasma-assisted chemical vapour deposition (PECVD), from a mixture of silane and hydrogen. Optical and electrical properties of the i-layers are described. Finally, present performances and future perspectives for a high efficiency 'micromorph' (mc-Si:Hya-Si:H) tandem solar cells are discussed.
\end{abstract}

Keywords: micromorph tandem solar cell, silicon, amorphous solar 


\section{Introduction}

$\mathrm{I}$ n 1994, our group at Institute of Microtechnology (IMT) Neuch\#atel succeeded in the preparation of a fully microcrystalline (mc-Si:H) silicon $\mathrm{p}-\mathrm{i}-\mathrm{n}$ singlejunction solar cell with new striking advantages compared to amorphous silicon (a-Si:H) [1]: This new photovoltaic absorber material shows no light-induced degradation unlike a-Si: $\mathrm{H}$, and has a lower band gap than a-Si:H, i.e. a higher current potential for solar cells. In the same year, IMT also presented the "micromorph" concept consisting of an amorphous silicon top cell and a microcrystalline silicon bottom cell [2]. This original work was pioneered from the beginning in the "superstrate configuration", e.g. $\mathrm{p}-\mathrm{i}-\mathrm{n} / \mathrm{p}-$ i-n tandem cells were deposited on a glass substrate coated with transparent conductive oxide (TCO). With this new concept, stabilized cell efficiencies in the range of $11-12 \%$ have been achieved [3-7]. This type of thin film solar cell, based on silicon alone, is today considered to be one of the most promising cell concepts with respect to cost reduction with simultaneous efficiency enhancement, availability of raw materials and technological feasibility of upscaling to large-area modules. For the deposition of microcrystalline silicon, the same deposition equipment can, in principle, be used as in the case of amorphous silicon. The latter is at present the only thin-film solar cell that has established itself forMWscale manufacturing. Recently, Kaneka Corp. changed their strategy by adopting IMT's original concept of a superstrate micromorph tandem configuration deposited on glass (called "hybrid" solar cells by them) and visibly substantially reducing their deposition temperature. Thereby, they were able to fabricate large-area PV "micromorph" or "hybrid" modules of $0.4 \mathrm{~m} 2$ size [8], that have since been introduced into the European market. These modules show initial efficiencies close to $10 \%$, which are well above those that are currently obtained for commercially mass-produced amorphous silicon-based solar modules. Thus, one can say that micromorph tandems open up a new efficiency segment range for thin-film solar cells; indeed, they have the potential for overlapping with the region of wafer-based solar cells, especially when taking the better temperature coefficient of micromorph tandems into account and considering solar module performance under real outdoor working conditions $[4,8]$.

As crystalline silicon is a material with an indirect band gap, the optical absorption coefficient for photon energies just over the band gap is relatively low. This means that in a micromorph tandem, the microcrystalline bottom cell will have to be thicker than the amorphous top cell in order to obtain current matching conditions. The challenge of making micromorph cells economically viable is given therefore not only by the question of obtaining higher efficiencies, but by the technological aspect of achieving high deposition rates and the further aspect of optimizing the light-trapping for the thin-film cell. A highly efficient lighttrapping allows for the reduction of the thickness of the mc-Si:H bottom cell, and a high deposition rate allows for a high throughput. Both are important factors for the economical manufacturing of micromorph tandems. The key question is to what extent the mc-Si:H cell thickness can be reduced while still achieving optimal efficiency potential for micromorph modules. In this article, we present the result of high effieciency a-Si:H/a-Si:H tandem solar cell.

There are two forms of thin-film silicon material that can be used for constituting such a solar cell: hydrogenated amorphous silicon (a$\mathrm{Si}: \mathrm{H})$ and hydrogenated microcrystalline silicon (mc-Si:H).

\section{Amorphous silicon (a-Si:H)}

Amorphous silicon (a-Si:H) layers were first deposited by R. Chittick.1 He was experimenting with silane ( $\mathrm{SiH} 4)$ plasmas and accidentally obtained a-Si:H layers in a remote part of his plasma reactor. Chittick's results were taken up by W. E. Spear and co-workers at Dundee University, who published3 the first systematic study on plasma-enhanced chemical 
vapour deposition (PECVD) with silane plus (optional) doping gases: Figure 1 shows schematically the results obtained by W. E. Spear et al.3 by plotting the values of dark conductivity and dark conductivity activation energy $\mathrm{E}_{-}$ against gas phase doping ratio. Also plotted is the estimated position of the resulting Fermi level Ef, obtained by taking the E_ values and correcting for the so-called statistical shift One can see from Figure 1 that it is possible, albeit in a very imperfect manner, to dope a-Si:H layers. This is contrary to the experience with most other amorphous semiconductor layers, and it enables one to build actual semiconductor devices with a-Si:H layers. It is, however, not advisable to use p-n-type diodes as solar cell structure, in the case of amorphous silicon, and this for three reasons:

- The doping capability of a-Si:H is rather poor, the Fermi-level can be pushed only half way towards the conduction and valence band edges, even with heavy doping-this can be seen in Figure 1.

- Doping has a detrimental effect on a-Si:H layer quality, because it leads to the creation of many additional silicon dangling bonds, which are the main recombination centres in this material.

- In a classical p-n-type solar cell, carrier collection is obtained by minority carrier diffusion within the $\mathrm{p}$ - and n-layers. Luckily, diffusion lengths in crystalline silicon wafers are sufficiently high (over $200 \mathrm{~mm}$ ), to ensure a near-perfect carrier collection over the whole useful range of the solar cell thickness where significant optical absorption takes place. In a-Si:H layers, on the other hand, minority carrier diffusion lengths are extremely small (around 0_1 mm), and it becomes impossible to base the collection of photogenerated carriers on diffusion alone.

Because of these three reasons $\mathrm{p}-\mathrm{i}-\mathrm{n}$ diodes are always used for a-Si:H solar cells. The corresponding structure is shown schematically in Figure 2. In such a p-i-n cell the main part of light absorption and photogeneration of carriers will take place in the intrinsic (i) part of the solar cell. The p-i-n-type a-Si:H solar cell was introduced by D. Carlson et al. at RCA Laboratories, Princeton, New Jersey, USA.

In the first years after their introduction, $\mathrm{p}-$ i-n-type amorphous silicon solar cells made rapid progress in reaching higher efficiencies. By 1982, a-Si:H solar cells with (initial) efficiencies over $10 \%$ had been obtained. However, a-Si:H solar cells suffer from a light-induced degradation effect (the so-called StaeblerWronski effect) 7 and stabilize only at lower efficiency values.

\section{Thin-film crystalline (microcrystalline) silicon solar cells}

The use of thin-film silicon for solar cells is one of the most promising approaches to realize both high performance and low cost due to its low material cost and ease of manufacturing. Part of the motivation behind these studies comes from the theoretical finding that if these devices can be constructed so that they trap sufficient light, it should ideally be possible to achieve photoelectric conversion efficiencies in excess of $20 \%$, even with solar cells in which the photoelectric layer is just a few $1 \mathrm{~m}$ thick (Spitzer et al., 1980). Attention has recently been focused on thin-film solar cells made with crystalline silicon having a small grain size formed by plasma CVD using inexpensive substrate materials such as glass (Meier et al., 1994, 1996; Yamamoto et al., 1994, 1998, 1999; Yamamoto, 1999) and by using low temperatures regardless of the type of substrate instead of these hightemperature processes.

Fig. 2 shows the relationship between grain size and Voc (open circuit voltage) as summarized by Werner of Stuttgart University (Werner and Bergmann, 1999). Here, Voc can be regarded as a parameter reflecting the cell characteristics and crystalline properties. As the figure shows, superior characteristics are obtained with a grain size of $100 \mathrm{~lm}$, but the characteristics are worse with a grain size of a few tens of $\mathrm{lm}$. Conversely, favorable characteristics have been obtained experimentally both at Neuchâtel University (Meier et al., 1994, 1996) and at Kaneka Corporation (Yamamoto et al., 1994, 1998, 1999; Yamamoto, 1999) by using thin-film crystalline silicon formed at low temperatures by plasma 
CVD with a submicron grain size (this is generally referred to as microcrystalline silicon due to the small grain size). This is an interesting discovery which has caused recent research to shift toward both extremes (one is small grain size, the other is mono-crystalline such as layer transfer method

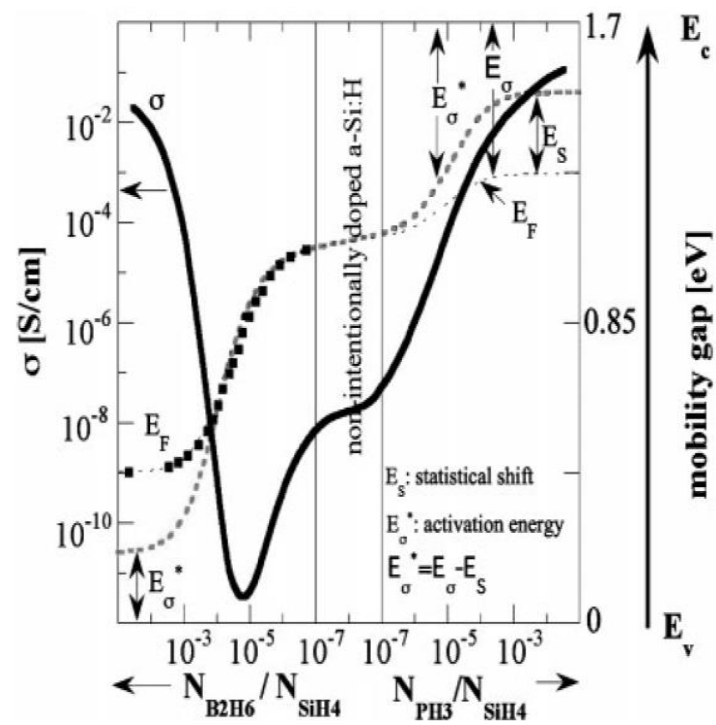

Figur1 1: Measured value of dark conductivity _ measured value of activation energy $E_{-}$of dark conductivity and estimated position of Fermi level Ef for a-Si:H layers, produced by PECVD on glass, in function of gas phase doping ratio $\mathrm{NPH} 3 / \mathrm{NSiH} 4$ (for n-type layers) and NB2H6/NSiH4 (for p-type layers). Values of _ and $E_{-}$are from, $3 \mathrm{E}_{-}{ }^{*}$ is here the estimated 'true' distance between band edge (Ec, Ev) and the Fermi level Ef, where the statistical shift Es has additionally been taken into consideration for n-type layers according to, 4 assuming thereby a constant defect density of $1016 / \mathrm{cm} 2$ $\mathrm{eV}$. For p-type layers, an identical correction Es has been assumed. The equivalent bandgap of a-Si:H, or the 'mobility gap' as it is called here, is taken to be $1 \_7 \mathrm{eV}$, while drawing the graph; this corresponds to the generally published valueDensidade.

Microcrystalline silicon solar cells formed by plasma CVD at low temperature are assumed to have a shorter carrier lifetime than single-crystal cells, and it is common to employ a $\mathrm{p}-\mathrm{i}-\mathrm{n}$ structure including an internal electric field in the same way as an amorphous solar cell. A p-i$\mathrm{n}$ type microcrystalline silicon solar cell is formed by a process fairly similar to that of an amorphous solar cell. Strictly speaking, these cells can be divided into $\mathrm{p}-\mathrm{i}-\mathrm{n}$ and $\mathrm{n}-\mathrm{i}-\mathrm{p}$ types according to the film deposition order, although the window layer of the solar cell is the p-type layer in both cases.

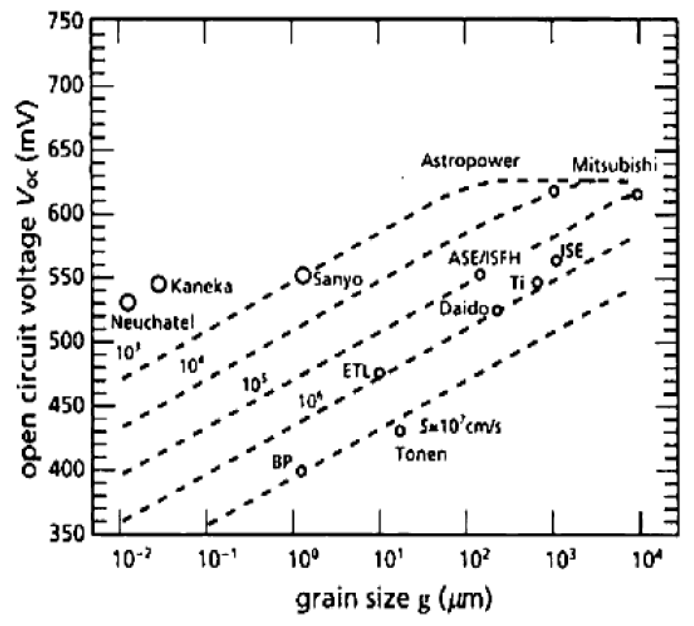

Figur2 2: The relationship between grain size and open circuit voltage (Voc) in solar cells. $\mathrm{Voc}$ is correlated to the carrier lifetime (diffusion length). In the figure, $\mathrm{S}$ indicates the recombination velocity at the grain boundaries. In this paper, microcrystalline silicon cells correspond to a grain size of $0.11 \mathrm{~m}$ or less. In the figure, $\mathrm{Ti}, \mathrm{BP}, \mathrm{ASE}$ and ISE are abbreviations of the research facilities from which the associated data came.

The characteristics of a cell having a $\mathrm{p}-\mathrm{i}-\mathrm{n}$ structure were first reported by Neuchatel University (Meier et al., 1994, 1996). Unlike an amorphous solar cell, this cell does not deteriorate when exposed to light. The very first reports on the characteristics of an nip cell were made by our group using the light trapping structure described below. These cells had an intrinsic conversion efficiency of $10.7 \%$ and an apparent efficiency of $10.1 \%$ for a film thickness of $2 \operatorname{lm}$ (surface area $1 \mathrm{~cm} 2$, measured by the JQA (Japan Quality Assurance Organization) (Fig. 3) (Yamamoto et al., 1998, 1999; Yamamoto, 1999). Also, by subjecting the silicon film in the photoelectric layer of this cell to XRD (X-ray diffraction) measurements, it was found to have a preferential (110) orientation. The $\mathrm{p}-\mathrm{i}-\mathrm{n}$ and $\mathrm{n}-$ i-p cells have different characteristics due to their different fabrication sequences. A large difference is that the underlying layer of a $\mathrm{p}-\mathrm{i}-\mathrm{n}$ cell is the transparent p-type electrode, whereas 
the underlying layer of a $n-i-p$ cell is the n-type back electrode.

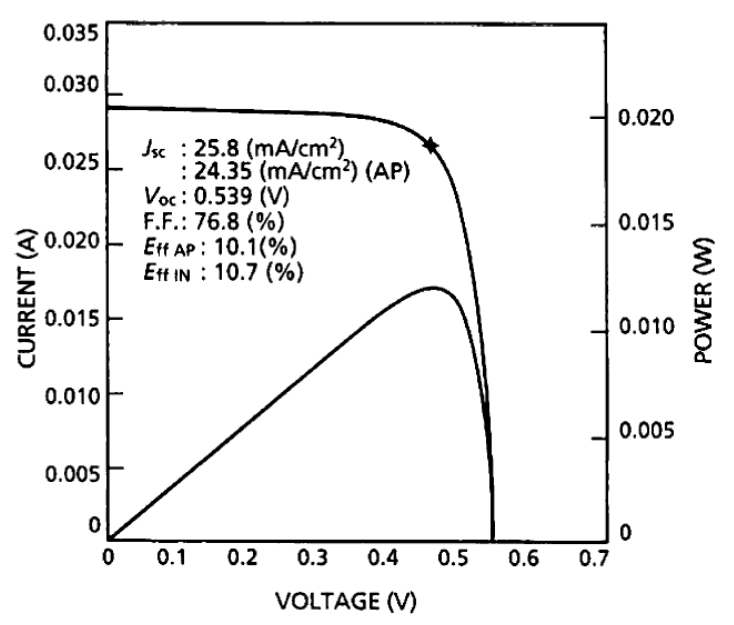

Figur3 3: Current-voltage characteristics of an $\mathrm{n}-\mathrm{i}-\mathrm{p}$ type microcrystallinesilicon cell (film thickness $21 \mathrm{~m}$, area $1 \mathrm{~cm} 2$, measuredby JQA). In this figure, EffAP is the characteristic for the areaincluding the grid electrode, and EffIN is the characteristic of the effective area not including the grid.

As a general rule, transparent electrodes are made of oxides, and since there is a risk of these oxides being reduced by the hydrogen atoms that are needed to form microcrystalline cells, there is a smaller process window in the cell formation conditions for the $\mathrm{p}-\mathrm{i}-\mathrm{n}$ type. From the viewpoint of the ease with which integrated structures can be formed, which is a characteristic of thin-film solar cells, an advantage of $\mathrm{p}-\mathrm{i}-\mathrm{n}$ cells is that they can be formed as super straight modules using integration techniques similar to those used for amorphous silicon as described below. On the other hand, it should be possible to make integrated structures of $n-i-p$ cells by methods equivalent to those used for $\mathrm{Cu}(\mathrm{InGa}) \mathrm{Se} 2-\mathrm{based}$ solar cells (Wieting et al., 1995). At the present time it is difficult to determine which is better, but it should become possible to arrive at a conclusion in terms of cost, performance and applications through the production of sub-modules in the future.

\section{4 “MICROMORPH" SOLAR CELLS}

The combination of an amorphous silicon top cell with a microcrystalline silicon bottom cell to form a stacked tandem cell is called the micromorph cell. In Fig. 4 a SEM cross section of a micromorph cell and is shown. Fig. 5 shows the cross section of the high efficiency micromorph solar cell using Silavo.

The two different gap energies involved in the micromorph tandem cell of the top and of the bottom cell make a striking difference to the well-known double-junction a-Si:H=a-Si:H tandem cell. The concept of superposing two a$\mathrm{Si}: \mathrm{H}$ cells is based on the reduction in the Staebler-Wronski effect that can be obtained by keeping each individual $i$-layer as thin as possible and not on a better utilization of the solar spectrum.

The objective here was to combine both our high quality amorphous $\mathrm{p}-\mathrm{i}-\mathrm{n}$ solar cells with the high Voc; high efficient microcrystalline $\mathrm{p}-\mathrm{i}-$ $\mathrm{n}$ cells and to prepare thus, high-Voc micromorph tandem devices.

The results of proposed tandem solar cell is shown in Fig. 6,7.

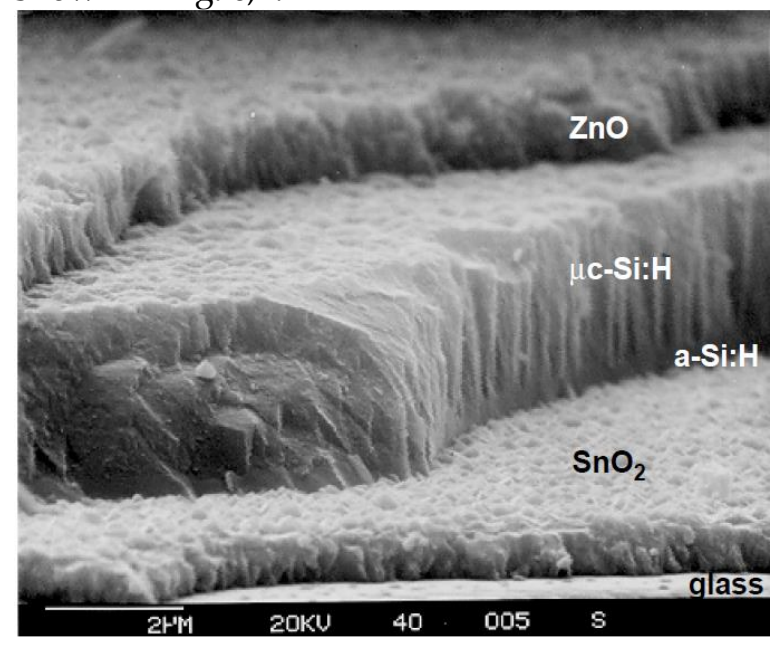

Figur4 4: Scanning electron micrograph (SEM) of the cross section of a micromorph tandem cell deposited on $\mathrm{SnO} 2$-coated glass 


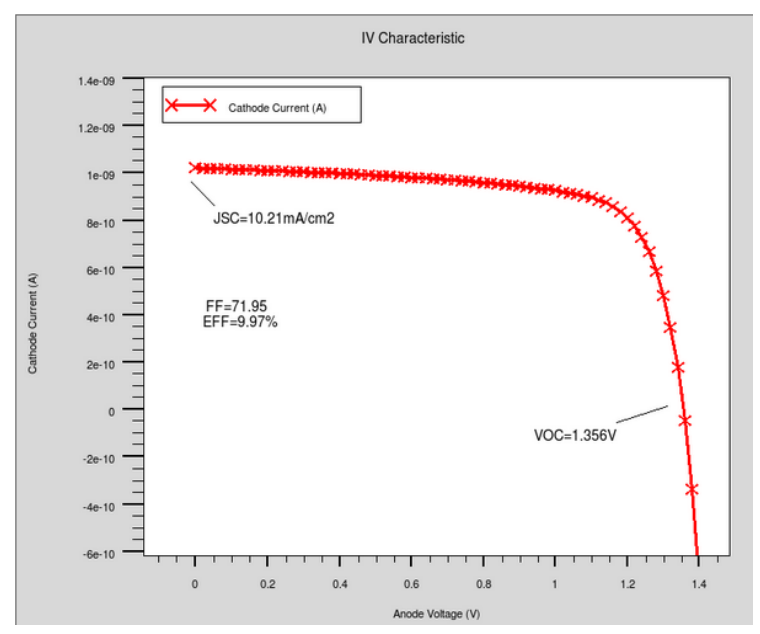

Figur5 5: JyV curve for proposed tandem solar cell

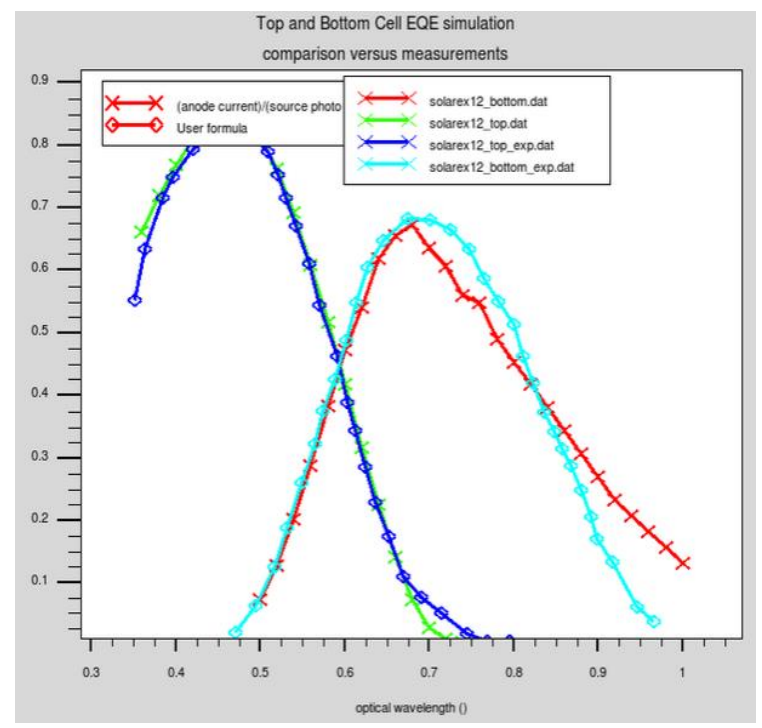

Figur6 6: comparison versus measurement

\section{Conclusions}

Microcrystalline silicon is not just an individual new absorber material for solar cells, it contains a large morphological variety as described by the so-called Thornton diagram [60, 61]. If one looks at the morphology of microcrystalline silicon the concept of an ideal isotropic semiconductor must be abandoned. Nevertheless, by varying the growth conditions, stable efficiencies of $10 \%$ can be achieved at deposition temperatures around 550 and of 8:5\% at 200 . It transpires that the parameter field for optimization of microcrystalline silicon, as a function of its deposition conditions (i.e. as a function of its position in the Thornton diagram) contains not only one set of parameters, but a large span of parameters. It is a function of deposition temperature, pressure, gas flows, the presence and nature of the plasma used for deposition. Photovoltaic research is at the moment just starting to exploit thin-film crystalline silicon as an absorber material. Micromorph solar cells improve the stable efficiency of amorphous solar cells due to a better utilization of the solar spectrum; stable efficiencies of about $12 \%$ could be achieved with further potential for improvement. Nevertheless, laboratory research has always also to be aware of industrial requirements, and here the efficiency is only one of the issues. All deposition methods of thin-film solar cell concepts have to fulfill demands for large-area manufacturing at low production costs. There is indeed hope that the thin-film micromorph solar cell concept described in this paper can constitute a link between high-efficiency silicon solar cells in form of wafers (that are too expensive) and the potentially low-cost amorphous silicon technology with presently low efficiencies. On can argue that the micromorph concept has the potential to become the concept for the next generation of thin-film solar cells, in view of its potential for high efficiency and low cost. One may also mention in this context the requirements of high reliability and of reduction in process energy and material flow. In this paper, we present the result of high efficiency aSi:H/a-Si:H tandem solar cell.

\section{References}

J. Meier, R. Fl. uckiger, H. Keppner, A. Shah, Appl. Phys. Lett. 65 (1994) 860

J. Meier, S. Dubail, R. Fl. uckiger, D. Fischer, H. Keppner, A. Shah, Proceedings of the First WCPEC, 1994, p. 409.

J. Meier, S. Dubail, J. Cuperus, U. Kroll, R. Platz, P. Torres, J.A. Anna Selvan, P. Pernet, N. Beck, Pellaton, N. Vaucher, Ch. Hof, D. Fischer, H. Keppner, A. Shah, J. Non-Cryst. Solids 227-230 (1998) 1250.

H. Keppner, J. Meier, P. Torres, D. Fischer, A. Shah, Appl. Phys. A 69 (1999) 169-177. 
K. Yamamoto, et al., J. Non-Cryst. Solids 266-269 (1-3) (2000) 1082-1087.

K. Saito, M. Sano, K. Matuda, T. Kondo, T. Nishimoto, K. Ogawa, I. Kajita, Proceedings of the Second WCPEC, 1998, p. 351.

K. Yamamoto, T. Suzuki, M. Yoshimi, A. Nakajima, Proceedings of the 14th EU PVSEC, 1997, p. 1018.

K. Yamamoto, M. Yoshimi, T. Suzuki, T. Nakata, T. Sawada, A. Nakajima, K. Hayashi, Proceedings of the 28th IEEE PVSC, 2000, p. 1428.

K. Yamamoto, M. Yoshimi, T. Suzuki, Y. Tawada, Y. Okamoto, A. Nakajima, Proceedings of the Second WCPEC, 1998, p. 1284.

. Vetterl, et al. Proc. Mater. Res. Soc. Symp. 609 (2000) A15.2.1; www.mrs.org.

Y. Nasuno, M. Kondo, A. Matsuda, Proceedings of the 28th IEEE PVSC, 2000, p. 142.

S.J. Jones, R. Crucet, M. Izu, Proceedings of the 28th IEEE PVSC, 2000, p. 134.

J. Dubail, et al. Proc.Mater. Res. Soc. Symp. 609 (2000) A13.6.1; www.mrs.org.

E. Vallat-Sauvain, U. Kroll, J. Meier, A. Shah, J. Pohl, J. Appl. Phys. 87 (2000) 3137.

J. Bailat, E. Vallat-Sauvain, L. Feitknecht, A. Shah, J. Non-Cryst. Solids 299-302 (2001) 1219.

S. Fa.y, S. Dubail, U. Kroll, J. Meier, Y. Ziegler, A. Shah, Proceedings of the 16th EU PVSEC, 2000, p. 361.

J. Meier, U. Kroll, S. Dubail, S. Golay, S. Fa.y, J. Dubail, A. Shah, Proceedings of the 28th IEEE PVSC, 2000, p. 746.

D. Carlson, et al. Proceedings of the 25th IEEE PVSC, 1996, p. 1023.

S. Golay, J. Meier, S. Dubail, U. Kroll, A. Shah, Proceedings of the 16th EU EPVSEC, 2000, p. 494.

S. Golay, J. Meier, S. Dubail, S. Fa.y, U. Kroll, A. Shah, Proceedings of the 28th IEEE PVSC, 2000, p. 1456. 